\title{
Implementation of Sobel Method Based Edge Detection for Flower Image Segmentation
}

\author{
Asmaidi \\ Polytechnic of South Aceh \\ Tapaktuan city, Indonesia \\ asmedmat@gmail.com \\ Muharratul Mina Risky \\ Polytechnic of South Aceh \\ Tapaktuan city, Indonesia \\ kiky.amiruddin@gmail.com
}

\author{
Darma Setiawan Putra \\ Polytechnic of South Aceh \\ Tapaktuan city, Indonesia \\ darma.poltas@gmail.com \\ Fitria Ulfa, R \\ Polytechnic of South Aceh \\ Tapaktuan city, Indonesia \\ roesdhayulfha@gmail.com
}

\begin{abstract}
Edge detection is the first step to cover information in the image. The edges characterize the boundaries of objects and therefore edges are useful for the process of segmentation and identification in the image. The purpose of edge detection is to increase the appearance of the boundary line of the object in the image. The sobel method is a method that uses two kernels measuring $3 x \mathbf{3}$ pixels for gradient calculations so that the estimate gradient is right in the middle of the window. Digital image processing aims to manipulate image data and analyze an image with the help of a computer. Matlab is made to facilitate the use of two collections of subroutines in the fortran library, linpack and eispack, in handling matrix computing, and develops into an interactive system as a programming language. Experimental results from the input image research, namely the flower image have different MSE values because each input image has a different pixel value.
\end{abstract}

Keywords - Edge detection, Sobel method, Matlab R2010a, Flower image segmentation

\section{INTRODUCTION}

\subsection{Background}

Edge Detection (Edge Detection) is an operation process to detect edges that limit two homogeneous image regions that have different brightness levels. The goal is to convert $2 \mathrm{D}$ images into curve shapes. This edge detection is one of the image processing techniques. Image processing transforms an image / image into another image using certain techniques (Darma Putra, 2010). This image processing includes several research topics including: computer graphics, image processing, and pattern recognition.

Image processing is done by transforming the image into another image with better image quality whose operations can include: image enhancement, image restoration, image compression, image segmentation, image analysis, etc. Based on the transformation objectives, image processing operations are categorized by Image Enhancement and Image Restoration (Darma Putra, 2010). In doing image processing, the Sobel method is used. The Sobel method is a method that uses two kernels measuring $3 x 3$ pixels to calculate the gradient so that the estimate gradient is right in the middle of the window. (Sutoyo et al., 2009).

\subsection{Research Problem}

Based on the background description of the problem above, the formulation of the problem is how is the Sobel method implementation of edge detection for the image segmentation of flowers?.

\section{Literature REVIEW}

\subsection{Digital Image}

Edge Detection (Edge Detection) is an operation process to detect edges that limit two homogeneous image regions that have different brightness levels. The goal is to convert 2D images into curve shapes. This edge detection is one of the 
image processing techniques. Image processing transforms an image / image into another image using certain techniques (Darma Putra, 2010). This image processing covers several research topics including: computer graphics, image processing, pattern recognition.

Image processing is done by transforming the image into another image with better image quality which operations can include: image enhancement, image restoration, image compression, image segmentation, image analysis, etc. Based on the transformation objectives, image processing operations are categorized by Image Enhancement and Image Restoration (Darma Putra, 2010). In doing image processing, the Sobel method is used. The Sobel method is a method that uses two kernels measuring $3 \times 3$ pixels to calculate the gradient so that the estimate gradient is right in the middle of the window. (Sutoyo et al., 2009).

\subsection{Definition of Digital Image and Image \\ Processing}

Image an image on a two-dimensional field. In a mathematical review, the image is a continuous function of the intensity of light on a two-dimensional field. When a light source illuminates an object, the object reflects back some of that light. This reflection is captured by optical sensing devices, such as the human eye, camera, scanner and so on. The shadow of the object will be recorded according to the intensity of the light reflection. When an optical device that records light reflection is a digital machine, for example a digital camera, then the resulting image is a digital image. In digital images, the continuity of light intensity is quantified according to the resolution of the recording device (Rinaldi Munir, 2004).

Digital image processing is a process that aims to manipulate and analyze images with the help of a computer. Digital image processing can be grouped into two types of activities (Darma Putra, 2010):

1) Improving image quality, so that it can be more easily interpreted by the human eye.

2) Processing information contained in an image for automatic object recognition.

\subsection{Binary image}

Binary imagery has 2 types of colors, namely black and white. So it takes 1 bit in memory to store these two types of colors (Darma Putra, 2010).

\subsection{Grayscale Image}

Grayscale image, is an image which pixel value represents the degree of gray or white intensity. The lowest intensity value is to represent black and the highest intensity value represents white. The number of colors in the type of grayscale image depends on the number of bits provided by the memory to hold. 2-bit images represent 4 colors, 3bit images represent 8 colors, and so on up to 8 bits (Darma Putra, 2010).

Based on Figure 3, it is enabled to observe the color gradation comparison from grayscale image. The larger the bit, the smoother the grayscale color is displayed.

\subsection{Skewing the RGB Image to Grayscale Image}

The Grayscale process is the main process of the edge detection process. This process is used to make the matrix a more concise image. The calculation that is often used is (Darma Putra, 2010):

\subsection{Edge Detection}

$$
X=\frac{(R+G+B)}{3}
$$

Edge detection is the first step to cover information in the image. The edges characterize the boundaries of objects and therefore edges are useful for the process of segmentation and identification in the image. The purpose of edge detection is to increase the appearance of the boundary of an area or object in the image. What is meant by edge is the change in the value of sudden intensity of the degree of gray (large) in a short distance (Wijaya E, 2012).

\subsection{Convolution Process}

Convolution in image processing can be found in a matrix, where each part of the matrix is called the convolution process coefficient by shifting the matrix to neighboring pixels with a depth of $3 \times 3$ and from the convolution results a new image is obtained.

\subsection{Image Segmentation}

Segmentation is a stage in the image analysis process that aims to obtain information in the image by dividing it into separate regions where each region is homogeneous and refers to clear criteria of uniformity and must be appropriate so that the information contained in it can be translated properly. Segmentation must be stopped if each object has been isolated or clearly visible. The level of accuracy depends on the level of success of the analysis procedures carried out and it is expected that the segmentation process has a high level of accuracy (Apriliani, D and Murinto, 2013).

\subsection{Sobel Method}

The sobel method is a method that uses two kernels measuring $3 x 3$ pixels to calculate the gradient. The gradient calculated using the sobel operator is as follows:

$$
G=\sqrt{S x^{2}+S y^{2}}
$$

Information:

$G$ : Sobel gradient operator value 


\section{$S_{x}$ : Horizontal horizontal gradient}

$S_{y}:$ Vertical sobel gradient

\section{Proposed Method}

\subsection{Types of Research}

The research is experimental research, which can be defined as a study which data can be obtained by recording directly from the results of the experiment. In addition, as a comparison, calculations and analyzes are carried out on the initial image and result image after edge detection.

\subsection{Data}

The data used in the study are images with jpg and png data types.

\subsection{System Requirement}

The system needed to build an image quality improvement program consists of hardware and software. The hardware (hardware) needed is a PC or laptop and printer. The software needed is an operating system (Windows 8), Matlab, and Microsoft Word.

\subsection{Flowchart}

Flowchart is a chart that shows flow in the program or system procedure logically. Used primarily for communication tools and for documentation.

\subsection{Design Process Methods}

The process of this research is generally described in the form of a flowchart as follows:

\subsection{Data Analysis Techniques}

In this study, the analysis is quantitative, a test is done using Mean Squared Error (MSE) to find out the average square of the error value between the original image segmentation. Mathematically, MSE can be formulated (Rinaldi Munir, 2004):

$$
\begin{aligned}
& \text { MSE }=\frac{1}{M N} \sum_{X}^{M}=1 \sum_{Y}^{N}=1[f(x, y)-g(x, y)]^{2} \\
& \text { Keterangan: } \\
& f(x, y): \text { Original image pixel value } \\
& g(x, y): \text { Segmented image pixel value } \\
& M, N \quad: \text { Image dimension }
\end{aligned}
$$

\section{RESULT AND DISCUSSION}

\subsection{Result and Discussion}

Development of this application is based on the design discussed in the literature review. From the design, it is implemented in the form of matlab files that are used in making and running a program. The implementation of edge detection based on the Sobel method for image flower segmentation.

\subsubsection{Original Image}

The original image is a page that contains original images consisting of 6 kinds of flower images including sunflower imagery, jasmine flower image, amalanda flower image, paper flower image, rose flower image, and lotus flower image. The display of the original image page can be seen in Figure 8.

\subsubsection{Graysacale Conversion}

After inputting the original image, the image in the form of a color image (RGB) will be converted into an image of gray / grayscale. The process of converting flower images (RGB) to grayscale is done by using the rgb2gray function that is already in MATLAB. Display of pages Grayscale conversion can be seen in Figure 9.

\subsubsection{Edge Detection of Sobel}

The sobel method uses a $3 x 3$ matrix and the arrangement of pixels around pixels $(x, y)$ as the following chart:

\begin{tabular}{|c|c|c|}
\hline $\mathrm{a}_{0}$ & $\mathrm{a}_{1}$ & $\mathrm{a}_{2}$ \\
\hline $\mathrm{a}_{7}$ & $(x, y)$ & $\mathrm{a}_{3}$ \\
\hline $\mathrm{a}_{6}$ & $\mathrm{a}_{5}$ & $\mathrm{a}_{4}$ \\
\hline
\end{tabular}

From the flow diagram described earlier, it can be explained that the edge detection process using the sobel method is as follows:

1) Calculate the value of the $x$-gradient

$S_{x}=\left(\mathrm{a}_{2}+\mathrm{ca}_{3}+\mathrm{a}_{4}\right)-\left(\mathrm{a}_{0}+\mathrm{ca}_{7}+\mathrm{a}_{6}\right)$, with $\mathrm{c}$ as a constant 2 .

\begin{tabular}{|c|c|c|c|}
\hline \multicolumn{1}{c|}{$S_{x}$} & -1 & 0 & 1 \\
\cline { 2 - 4 }$=$ & -2 & 0 & 2 \\
\hline-1 & 0 & 1 \\
\hline
\end{tabular}

2) Calculate the value of $y$-gradient $S_{y}=\left(\mathrm{a}_{0}+\mathrm{ca}_{1}+\mathrm{a}_{2}\right)-\left(\mathrm{a}_{6}+\mathrm{ca}_{5}+\mathrm{a}_{4}\right)$, with $\mathrm{c}$ as constant 2 or mask/kernel.

$S_{y}=$\begin{tabular}{|c|c|c|}
\hline 1 & 2 & 1 \\
\hline 0 & 0 & 0 \\
\hline-1 & -2 & -1 \\
\hline
\end{tabular}

3) Calculate gradient magnitude

$$
|S|=\sqrt{S x^{2}+S y^{2}}
$$


4) The results of Sobel edge detection can be seen in Figure 10

\subsubsection{Evaluation stage (Calculation of mean value)}

Evaluation is done by testing to assess the accuracy of the method chosen in the process of flower image segmentation.

1) Mean Squard Error (MSE)

Testing is done by using Mean Squared Error (MSE) to find out the average squared error value between pre-segmentation images and segmentation images. Mathematically MSE can be formulated:

MSE $=\frac{1}{M N} \sum_{X}^{M}=1 \sum_{Y}^{N}=1[f(x, y)-g(x, y)]^{2}$

Information :

$f(x, y)$ : Original image pixel

$\mathrm{g}(\mathrm{x}, \mathrm{y})$ : Segmented pixel

$\mathrm{M}, \mathrm{N}$ : Image Dimension.

2) MSE Calculating Process

a. Calculating the pixel value of a reference image with the pixel value of the segmented image is then squared for each pixel.

b. Add the results of the calculation above.

c. Calculate image dimensions.

d. The result of step b calculation is then divided by the number of dimensions in step $\mathrm{c}$, the MSE value will be generated.

3) The measurement results are shown in Table 3:

Table 3 shows the results of the experiment using different MSE values for each flower image. From the evaluation results, it can be seen that this method can do the edge detection process well. The smaller the MSE is used, the smaller the size of the image produced and the results will increasingly resemble the original image.

\section{Conclusion ANd Suggestion}

Based on the results and discussion, conclusions and suggestions can be written as follows:

\subsection{Conclusion}

1) The use of the Sobel method on flower edge detection is the right step, because its edge detection is very optimum and produces a minimum pixel edge that detects the true edge.

2) The experimental results of 6 input images, for flower images, have different MSE values because each input image has a different pixel value.

\subsection{Suggestion}

1) The image acquisition process needs to be well planned, because the results of edge detection are strongly influenced by the image acquisition quality.

2) In order for smooth detection, the interest image acquisition process should use a different background with the color of the flower so that the identification of flowers is easier to recognize edge detection.

\section{FIGURES AND TABLES}

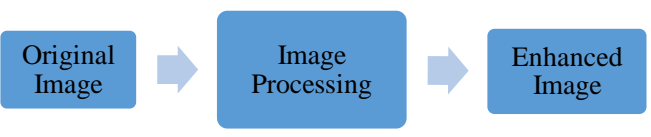

Fig 1. Image Processing

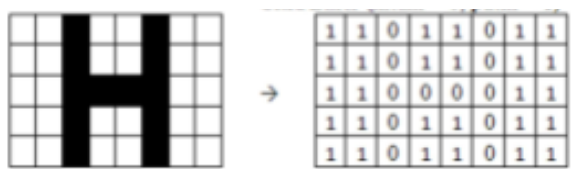

Fig 2. Binary Image $($ Black $=0$ and White $=1)$

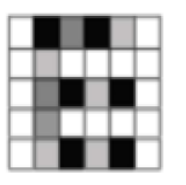

\begin{tabular}{|c|c|c|c|c|c|}
\hline 15 & 0 & 6 & 0 & 13 & 15 \\
\hline 15 & 12 & 15 & 15 & 15 & 15 \\
\hline 15 & 5 & 0 & 12 & 0 & 15 \\
\hline 15 & 8 & 15 & 15 & 15 & 15 \\
\hline 15 & 10 & 0 & 13 & 0 & 15 \\
\hline
\end{tabular}

Fig 3. Grayscale Comparison $($ Black $=0$ and White $=1)$

\begin{tabular}{|c|c|c|c|c|}
\hline \multirow{4}{*}{$\Rightarrow$} & 255255255 & 000 & 128128128 & 1281280 \\
\hline & 0255255 & 000 & 204255255 & 00255 \\
\hline & 150150150 & 515151 & 255255255 & 959595 \\
\hline & 250204153 & 255204253 & 12800 & 2550255 \\
\hline
\end{tabular}

Fig 4. Image Color Conversion

$\square \quad$\begin{tabular}{|c|c|c|c|}
\hline 255 & 0 & 128 & 85 \\
\hline 170 & 0 & 238 & 85 \\
\hline 150 & 51 & 255 & 95 \\
\hline 204 & 204 & 42 & 170 \\
\hline
\end{tabular}

Fig 5. Grayscale Conversion 


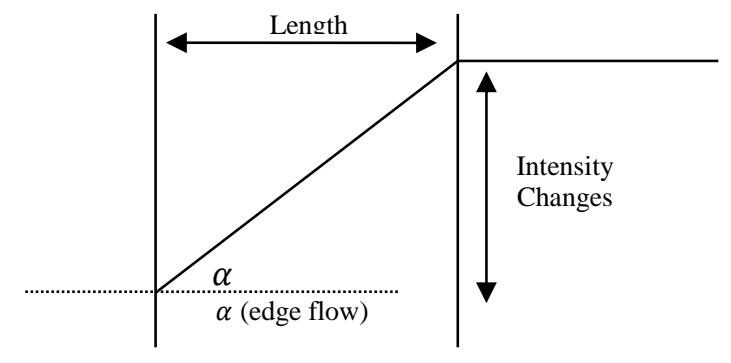

Fig 6. Edge Model in Uni-dimension

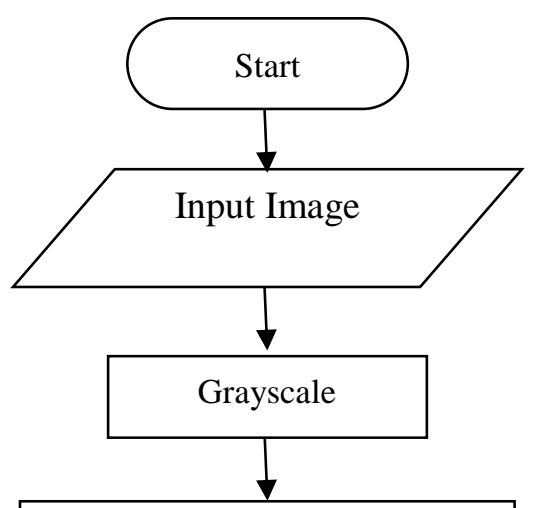

Sobel Edge Detection

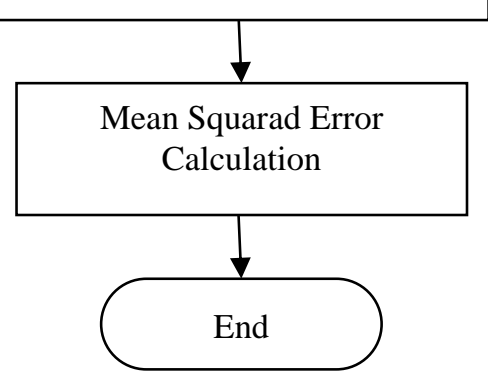

Fig 7. Flowchart of Segmented Flower Image Process

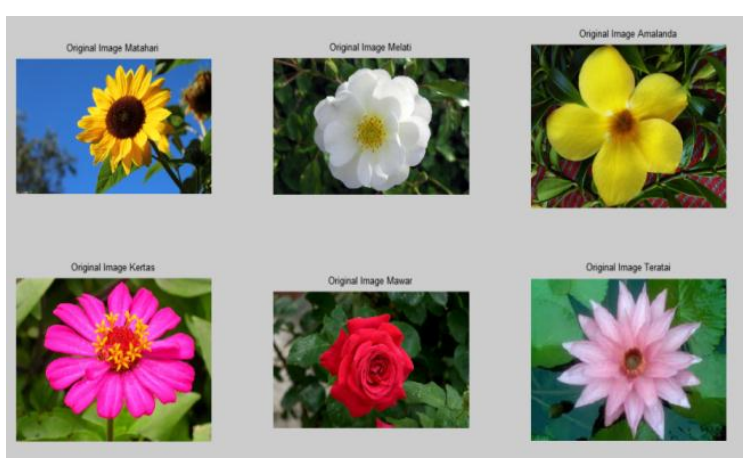

Fig 8. Original Image Page

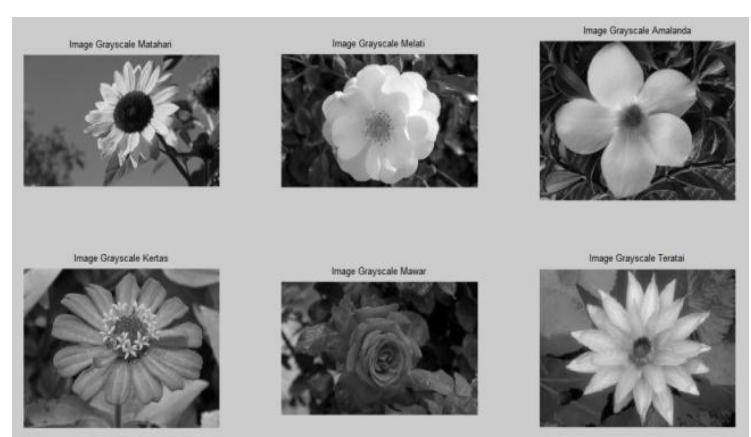

Fig 9. Grayscale Conversion
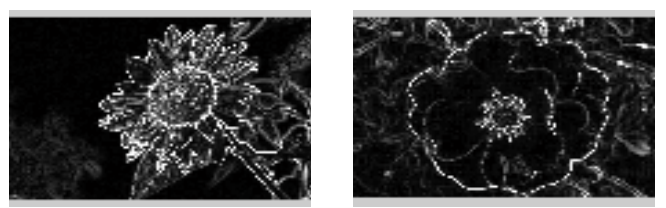

Sobel edge Detection

Sobel edge Detection:: Sunflower
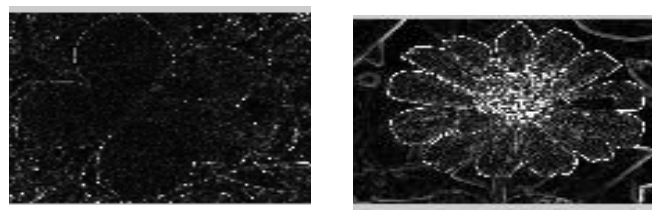

Sobel edge Detection Amalanda

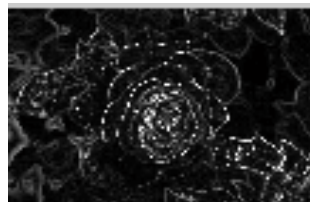

Sobel edge Detection : Rose

Sobel edge Detection Paper flower

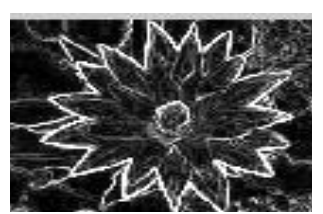

Sobel edge Detection : lotus

Fig 10. Flower Image after Sobel edge Detection

Table 1. Flowchart Symbols

\begin{tabular}{|l|l|}
\hline & \multicolumn{1}{|c|}{ Information: } \\
\hline & $\begin{array}{l}\text { Terminal : } \\
\text { Shows the beginning and end of a process }\end{array}$ \\
\hline & $\begin{array}{l}\text { Process, a symbol that shows every } \\
\text { processing carried out by a computer }\end{array}$ \\
\hline & $\begin{array}{l}\text { Input / Output: to enter data and show the } \\
\text { results of a process }\end{array}$ \\
\hline
\end{tabular}




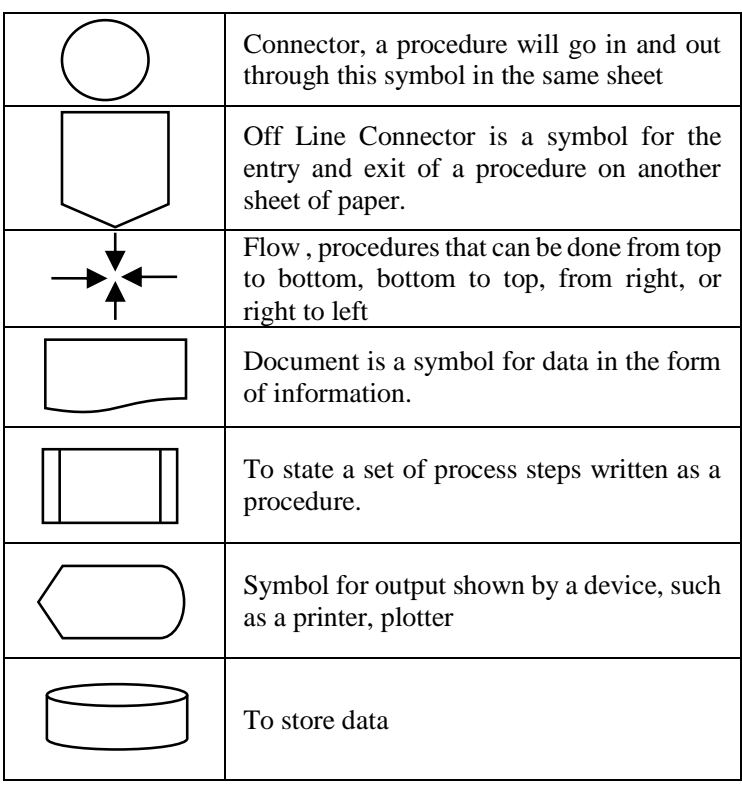

Table 2. Sobel Edge Detection

\begin{tabular}{|c|c|c|c|c|}
\hline No & Flower & $\begin{array}{c}\text { Original } \\
\text { Image }\end{array}$ & $\begin{array}{l}\text { Grayscale } \\
\text { Image }\end{array}$ & $\begin{array}{l}\text { Sobel Edge } \\
\text { Detection }\end{array}$ \\
\hline 1 & Sunflower & & & \\
\hline 2 & Jasmine & & & \\
\hline 3 & Amalanda & & & \\
\hline 4 & $\begin{array}{l}\text { Paper- } \\
\text { flower }\end{array}$ & & & \\
\hline
\end{tabular}

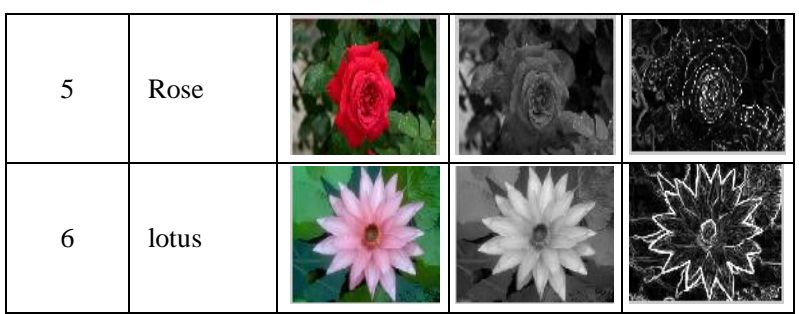

Table 3. MSE Value

\begin{tabular}{|c|l|c|}
\hline No & \multicolumn{1}{|c|}{ Image } & Nilai MSE \\
\hline 1 & Sunflower & 1.0548 \\
\hline 2 & Jasmine & 0.9835 \\
\hline 3 & Amalanda & 0.0378 \\
\hline 4 & paper-flower & 0.7353 \\
\hline 5 & Rose & 0.7574 \\
\hline 6 & lotus & 5.9868 \\
\hline
\end{tabular}

\section{ACKNOWLEDGMENT}

My graditute to research and community service center and head of informatics engineering study program for the support in completing this research.

\section{REFERENCES}

Apriliani. D dan Murinto. 2013. Analisis Perbandingan Teknik segmentasi Citra Digital Menggunakan Metode Level-Set Chan \& Vese dan Lankton, Jurnal Sarjana Teknik Informatika, Volume 1 Nomor 1, Juni 2013,

Darma Putra. 2010. Pengolahan Citra Digital. Andi Offset : Yogyakarta

Rinaldi Munir, 2004. Pengelohan Citra Digital dengan Pendekatan Algoritmik Informatika : Bandung

Sutoyo, T. et al. 2009. Teori Pengelohan Citra Digital : Andi Offset. Yogyakarta

Wijaya E. 2012. Analisis Intensitas Metode Pendekteksian Tepi Sobel, Jurnal Komputer dan Informatika (KOMPUTA), Edisi 1 Vol. 1 Maret 2012. 